\title{
Study of perinatal asphyxia and its outcome concerning nucleated RBC count in venous blood of term neonates
}

\author{
Kumar Jena P. ${ }^{1}$, Parida H. ${ }^{2}$, Swain B. ${ }^{3}$, Charan Murmu M. ${ }^{4 *}$ \\ DOI: https://doi.org/10.17511/ijpr.2021.i01.08 \\ ${ }^{1}$ Pradeep Kumar Jena, Associate Professor, Department of Pediatrics, S C B Medical College, Cuttack, Odisha, India. \\ 2 Himansu Parida, Resident, Department of Pediatrics, S C B Medical College, Cuttack, Odisha, India. \\ 3 Banashree Swain, Associate Professor, Department of Biochemistry, S C B Medical College, Cuttack, Odisha, India. \\ 4* Mangal Charan Murmu, Associate Professor, Department of Pediatrics, S C B Medical College, Cuttack, Odisha, India.
}

Introduction: Perinatal asphyxia is a serious problem globally and is one of the common causes of neonatal mortality. Worldwide each year four million infants suffer from birth asphyxia. Of these one million die and an equal number develop serious sequelae. Perinatal asphyxia ranks as the second most important cause of neonatal death after infections accounting for about $23 \%$ of mortality worldwide. Aim \& objective: To establish the level of nucleated red blood cells as an indicator of poor immediate outcome in perinatal asphyxia. Method: It was a case-control study done in the department of pediatrics, S C B Medical College \& S V P PG I P, Cuttack. Observation: The NRBC count was significantly higher in neonates with adverse outcomes than in those with favourable outcomes ( $p$-value $<0.001$ ). NRBC count cut-off of $>27 / 100$ WBC had a sensitivity of $75 \%$ and specificity of $95.2 \%$ in predicting adverse outcome defined as death, hemiplegia, hypertonia or significant hypotonia, unreliable sucking and seizures resistant to Phenobarbital. Conclusion: Nucleated red blood cell count can be used as a surrogate marker for birth asphyxia. It has a significant negative correlation with Apgar score at one minute and Apgar score at 5minutes \& significant positive correlation with severity of hypoxic ischemic-encephalopathy, time is taken for recovery of neurological impairment following birth asphyxia and duration of NICU stay.

Keywords: Neonates, Birth asphyxia, Hypoxic Ischemic Encephalopathy, Nucleated RBC

Corresponding Author

Mangal Charan Murmu, Associate Professor, Department of Pediatrics, S C B Medical College, Cuttack, Odisha, India.

Email: mangal74murmu@yahoo.co.in
How to Cite this Article

To Browse

Jena PK, Parida $H$, Swain B, Murmu MC. Study of perinatal asphyxia and its outcome concerning nucleated RBC count in venous blood of term neonates. Pediatric Rev Int J Pediatr Res. 2021;8(1):54-63.

Available From

https://pediatrics.medresearch.in/index.php/ijpr/arti

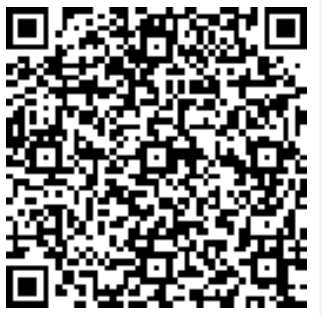
cle/view/651

Manuscript Received 2021-01-06

Conflict of Interest No
Review Round 1 2021-01-16

Funding Nil
Review Round 2 2021-01-22

Ethical Approval Yes
Review Round 3

Plagiarism X-checker $8 \%$
Accepted 2021-01-27

Note

(C) 2021 by Pradeep Kumar Jena, Himansu Parida, Banashree Swain, Mangal Charan Murmu and Published by Siddharth Health Research and Social Welfare Society. This is an Open Access article licensed under a Creative Commons Attribution 4.0 International License https://creativecommons.org/licenses/by/4.0/ unported [CC BY 4.0]. 


\section{Introduction}

Birth asphyxia is a serious clinical problem worldwide and contributes greatly to neonatal mortality and morbidity [1]. The incidence of birth asphyxia is about $1-1.5 \%$ of live births in most centres and inversely related to gestational age, and birth weight, lower considerably in later gestation [2].

According to the latest estimates by the World Health Organization (WHO), approximately 4 million babies die each year before they reach the age of one month. Ninety-eight Percent of these neonatal deaths take place in developing countries. Perinatal Asphyxia and birth injuries together contribute to almost $29 \%$ of these deaths [3]. Of the 1.2 million neonatal deaths in India every year, 300,000 to 350,000 infants die due to perinatal asphyxia mostly within the first three days of life [4].

WHO defines birth asphyxia as failure to initiate and sustain breathing at birth [5]. The National Neonatal and Perinatal Database (NNPD) defines perinatal asphyxia as an Apgar score of $<7$ at one minute of life. NNPD also defines moderate asphyxia as slow gasping breathing or an Apgar score of 4-6 and severe asphyxia as no breathing or an Apgar score of 0-3 at one minute of life [4].

Several methods like scoring systems, markers (non-protein bound iron, interleukin-6), EEG, cerebral function monitoring, imaging modalities (USG, CT, MRI) have been developed for early identification of neonates at high risk for brain injuries who may benefit from early neuroprotective interventions like induced mild hypothermia, antioxidant agents (allopurinol) and calcium channel blockers $[6,7,8,9]$. Further complications can be anticipated and corrective and preventive measures can be undertaken.

Most of the diagnostic and prognostic parameters used are available in few selected tertiary care hospitals, are expensive and require sophisticated equipment thus rendering them unreachable for most of the population. This problem is further compounded in a country like India where there is a wide gap between the need and accessibility of health services. Therefore there is a need for simple tests to identify perinatal asphyxia.

Studies have been done to correlate many nucleated red blood cells (NRBC) in cord blood with perinatal asphyxia and they have shown a good correlation $[10,11,12,13]$.
An increase in NRBC has been proposed due to increased production of erythropoietin secondary to perinatal asphyxia [14]. Most studies in the literature have used cord blood to report NRBC count. In developing countries like India, it is often difficult to collect cord blood as a large number of deliveries takes place in peripheral health centres or at home. NRBC count in venous blood can be a costeffective and logistically plausible alternative to cord blood NRBC. Hence the present study is intended to evaluate the significance of the presence of NRBC per 100 WBC in venous blood in the prediction of perinatal asphyxia and its outcome; and to compare this with established markers such as Apgar score.

\section{Aim \& objective}

To compare the levels of nucleated red blood cells in the venous blood of asphyxiated newborns with non asphyxiated newborns \& establish the level of nucleated red blood cells as an indicator of poor immediate outcome in perinatal asphyxia.

\section{Methodology}

After obtaining clearance from the institutional ethical committee(438/14/10/2020) the study was conducted in the Department of Pediatrics, S V P PG Institute of Pediatrics \& S C B Medical College, Cuttack. The parents willing to participate in the study were well informed in their locally understandable language, written consent was obtained thereof. The study was conducted from June 2018 to August 2020. It was a case-control study. With the help of a bio-statistician sample size was determined to be 100 which include 50 cases and 50 controls for the study by the purposive sampling method. Group 1 was the study group with the asphyxiated babies and Group 2 controlled with normal term babies without birth asphyxia.

\section{Selection criteria:}

Inclusion Criteria: Term neonates with perinatal asphyxia with 1 -min Apgar of $\leq 6 / 10$ as defined by WHO and NNPD.

Exclusion Criteria: Following babies were excluded from the study 1 .Newborns born with severe congenital anomalies, 2 . The baby having Chromosomal anomalies like Down's syndrome. 3. Babies with TORCH infections. 4. Sepsis, 5.Rh incompatibility causing hemolysis, 6. Maternal diabetes mellitus, 7. Multiple gestations, 8. Chorioamnionitis, 9. Intrauterine growth retardation 
10. Pre-eclampsia, pregnancy-induced hypertension, 11. Mothers on medications that change haematological profile like thiazides, angiotensinconverting enzyme inhibitors, beta-blockers.

Thilaganathan et al found significant differences in cord NRBCs of infants born by emergency caesarean section (median $=1100 \mathrm{NRBCs} / \mathrm{mm} 3$ ) compared with infants born by elective caesarean section (median $=300 \mathrm{NRBC} / \mathrm{mm} 3$ ) Therefore, babies born of emergency caesarean section were excluded from both study groups.

Controls: The Term neonates delivered during the same period, fulfilling the following criteria were enrolled as controls:1.Apgar scores $\geq 7$ at 1 minute, 2. Absence of meconium-stained amniotic fluid,3. Meeting the exclusion criterion described for the cases group.

Details data of the maternal parameters like age, blood group, haemoglobin level, past obstetric history, present pregnancy, medical history, medications taken during pregnancy, details of labour and delivery were recorded in a predesigned proforma.

So also details data of the baby like date\& time of birth, sex, gestational age, birth weight, Apgar score at one and five minutes, resuscitation if required (American Academy of Paediatrics guidelines) and examination details were recorded. Clinical assessments include assessments of the neurologic status daily during the stay, the grade of HIE (Stage I, Stage II or Stage III), the type of respiratory support needed, the presence of seizures and involvement of multiorgan dysfunction.

The time taken for the establishment of full oral feedings through sucking, time is taken for recovery of neonatal reflexes, duration of hospital stay and neurological examination at discharge were also noted. Laboratory assessments include routine NICU protocol investigations for birth asphyxia. Gestational age was assessed by using New Ballard's scoring. Hypoxic-ischemic encephalopathy if the present was graded using Sarnat and Sarnat staging.

Laboratory Investigation: Two $\mathrm{ml}$ of peripheral venous blood was collected within 6 hours of birth in ethylene diamine tetraacetate bulbs from both cases and controls. Samples were stored in the refrigerator if there was any delay in processing. Blood samples were used for making smears (for NRBCs) and complete blood count.
Babies with birth asphyxia were further admitted to NICU and investigated as per the routine NICU protocol for birth asphyxia.

Samples were processed and analyzed by the same blinded pathologist. The ethylenediamine tetraacetate sample was processed by SYSMEX automated cell counter for obtaining total white cell count and platelet count. The blood smears were stained by Leishman stain and the manual differential count was done to count NRBCs, toxic granules and band forms. Number of nucleated red blood cells were counted per 100 leukocytes in peripheral smears and were reported as 'number of NRBC/100WBC'.

Statistical Methods: Descriptive statistics, i.e. Mean \pm Standard deviation were calculated for every continuous variable in the study and frequency distribution tables were made for the categorical variables. To compute the correlation between two quantitative variables, Pearson's correlation coefficient was applied. For statistical analysis both study groups were divided into three groups according to NRBC count. The first group had an NRBC count of $0-9$, the second had an NRBC count of 10-19 and the third group had an NRBC count of 20 and more. To compute the difference between the asphyxiated and the non-asphyxiated group, Student t-test, Chi square-test and one-way ANOVA was applied as appropriate. The receiver operating curve (ROC) was used to derive the cut-off value for NRBC count for predicting perinatal asphyxia as well as to predict adverse outcome in perinatal asphyxia. A p-value of $<0.05$ was considered statistically significant. The results are presented as means ( \pm S.D.) unless otherwise indicated. All data were statistically analyzed using SPSS statistics software for Windows (Version 20).

\section{Observationv}

Table-1: Distribution of cases according to different parameter

\begin{tabular}{|l|l|l|l|c|}
\hline \multicolumn{2}{|c|}{ Parameter } & \multicolumn{1}{|c|}{$\begin{array}{c}\text { Study group- number } \\
(\%) \text { n=50 }\end{array}$} & $\begin{array}{c}\text { Control- number } \\
(\%) \text { n=50 }\end{array}$ & $\begin{array}{c}\text { p- } \\
\text { value }\end{array}$ \\
\hline \multirow{3}{*}{ Sex } & Male & $35(70 \%)$ & $26(52 \%)$ & 0.065 \\
\cline { 2 - 4 } & Female & $15(30 \%)$ & $24(48 \%)$ & \\
\hline \multirow{3}{*}{ Parity } & Gravida 1 & $36(72 \%)$ & $35(70 \%)$ & \multirow{2}{*}{0.414} \\
\cline { 2 - 4 } & Gravida 2 & $12(24 \%)$ & $11(22 \%)$ & \\
\cline { 2 - 4 } & Gravida 3 & $1(2 \%)$ & $4(8 \%)$ & \\
\cline { 2 - 4 } & Gravida 4 & $1(2 \%)$ & 0 & \\
\hline
\end{tabular}




\begin{tabular}{|l|l|l|l|l|}
\hline Presentation of delivery & Cephalic (vertex) & $49(98 \%)$ & $50(100 \%)$ & 1.000 \\
\cline { 2 - 4 } & Face & $1(2 \%)$ & 0 & \\
\cline { 2 - 4 } & Breech & 0 & 0 & \\
\cline { 2 - 4 } & Footling & 0 & 0 & \\
\hline Mode of delivery & Normal vaginal & $44(88 \%)$ & $49(98 \%)$ & \multirow{3}{*}{0.111} \\
\cline { 2 - 4 } & Caesarean section & 0 & 0 & \\
\cline { 2 - 4 } & Breech & 0 & 0 & \\
\cline { 2 - 4 } & Forceps & $6(12 \%)$ & $1(2 \%)$ & \\
\cline { 2 - 4 } & Vacuum & 0 & 0 & \\
\hline
\end{tabular}

There was no statistically significant difference between cases and controls. Hence, cases and controls were similar in terms of sex distribution. $72 \%$ of cases and $70 \%$ of controls were born to primigravid mothers. $28 \%$ of cases and $30 \%$ of controls were born to multiparous mothers There was no statistically significant difference between the study groups in terms of parity of mother ( $p$ value0.414). In the present study, the maximum numbers of neonates were born through normal vaginal delivery, which includes 44 cases (88\%) and 49 controls (98\%). While the rest of the newborns were born through forceps vaginal delivery which include 6 cases (12\%) and 1 control (2\%).

Table-2: Distribution of study groups according to the risk factors for perinatal asphyxia

\begin{tabular}{|c|c|c|c|}
\hline Parameter & $\begin{array}{c}\text { Study group- number } \\
(\%) n=50\end{array}$ & $\begin{array}{c}\text { Control- number } \\
(\%) n=50\end{array}$ & value \\
\hline Age of mother (years) & $22.64 \pm 2.56$ & $22.98 \pm 3.43$ & 0.278 \\
\hline Primi & $36(72 \%)$ & $35(70 \%)$ & 0.414 \\
\hline Multipara & $14(28 \%)$ & $15(30 \%)$ & 0.414 \\
\hline $\begin{array}{l}\text { Gestational age } \\
\text { (weeks) }\end{array}$ & $39.82 \pm 0.77$ & $39.36 \pm 0.77$ & 0.003 \\
\hline Birth weight $(\mathrm{kg})$ & $2.93 \pm 0.34$ & $2.80 \pm 0.37$ & 0.071 \\
\hline $\begin{array}{l}\text { Meconium stained } \\
\text { amniotic fluid }\end{array}$ & $20(62.5 \%)$ & 0 & \\
\hline Prolonged labour & $6(18.8 \%)$ & 0 & \\
\hline Cord around neck & $1(3.1 \%)$ & 0 & \\
\hline Short stature & $1(3.1 \%)$ & 0 & \\
\hline $\begin{array}{l}\text { Secondary Arrest in } \\
\text { Descent }\end{array}$ & $1(3.1 \%)$ & 0 & \\
\hline $\begin{array}{l}\text { Antepartum } \\
\text { hemorrhage }\end{array}$ & 0 & 0 & \\
\hline Maternal drug intake & 0 & 0 & \\
\hline Oligohydramnios & 0 & 0 & \\
\hline Systemic disease & 0 & 0 & \\
\hline Birth injury & 0 & 0 & \\
\hline
\end{tabular}

Among the cases, the mean age of mothers (in years) was 22.64 years of which $72 \%$ were primiparous and the rest multiparous.
The mean gestational age in cases (39.82 weeks) was greater compared to the controls group (39.36 weeks) which was statistically significant. Other risk factors associated with perinatal asphyxia in cases included meconium-stained amniotic fluid (45\%) followed by prolonged labour (18.8\%), cord around the neck (10\%), short stature (3.1\%) and secondary arrest in descent (3.1\%). .The mean birth weight in babies with birth asphyxia was 2.93 $\pm 0.34 \mathrm{~kg}$. The mean birth weight of controls was $2.80 \pm 0.37 \mathrm{~kg}$. Hence, the mean birth weight of cases was greater than controls but it was not statistically significant.

Among controls the mean age of mothers (years) was 22.98 years in which $70 \%$ were primiparous and the rest multiparous. No other risk factors were present in the control groups.

Table-3: Distribution of cases according to methods of resuscitation used

\begin{tabular}{|l|l|l|}
\hline \multicolumn{1}{|c|}{ Resuscitation } & Number & $(\%)$ \\
\hline Bag and mask ventilation (BMV) & 16 & $32 \%$ \\
\hline $\begin{array}{l}\text { Endotracheal(ET) intubation+ positive } \\
\text { pressureventilation }\end{array}$ & 27 & $54 \%$ \\
\hline $\begin{array}{l}\text { Endotracheal intubation + positive pressureventilation + } \\
\text { Chest compression (ET + CC) }\end{array}$ & 3 & $6 \%$ \\
\hline $\begin{array}{l}\text { Endotracheal intubation + positive pressure } \\
\text { ventilation+Chest compression + Drugs(ET + CC+ } \\
\text { Drugs) }\end{array}$ & 4 & $8 \%$ \\
\hline
\end{tabular}

In the present study, 27 cases (54\%) required endotracheal intubation and positive pressure ventilation whereas only 16 cases (32\%) required to bag and mask ventilation for resuscitation. Three babies (6\%) required endotracheal intubation, positive pressure ventilation and chest compression and 4 babies additionally required drugs in the form of adrenaline and normal saline bolus for resuscitation.

Table- 4: Distribution of cases according to stages of HIE

\begin{tabular}{|l|l|l|l|}
\hline STAGES of HIE & Frequency & Percentage & NRBC Count (Mean \pm SD) \\
\hline HIE STAGE 1 & 12 & $24 \%$ & $11.33 \pm 3.2$ \\
\hline HIE STAGE 2 & 26 & $52 \%$ & $21.85 \pm 17.9$ \\
\hline HIE STAGE 3 & 12 & $24 \%$ & $25.92 \pm 8.0$ \\
\hline Total & 50 & $100 \%$ & P value 0.031 \\
\hline
\end{tabular}

The majority of the cases had HIE stage 2(52\%). HIE stage 3 was seen in $24 \%$ of the cases. The remaining 12 cases (24\%) had HIE stage 1

Table-5: Hematological investigations in the study groups 
Jena PK. et al: Study of perinatal asphyxia and its outcome concerning

\begin{tabular}{|l|l|l|l|}
\hline \multicolumn{1}{|c|}{ Parameter } & Cases(mean) & Control(mean) & p-value \\
\hline Total leukocyte count & 18,101 & 17,771 & 0.765 \\
\hline Neutrophils (\%) & 54.7 & 62.06 & 0.010 \\
\hline Lymphocyes (\%) & 36.4 & 29.3 & 0.012 \\
\hline Monocytes (\%) & 4.78 & 5.94 & 0.065 \\
\hline Eosinophils (\%) & 3.5 & 3.51 & 0.067 \\
\hline Platelet count (x105/mm3) & 1.49 & 3.51 & 0.010 \\
\hline NRBC count ( $/ 100 \mathrm{WBC})$ & 20.3 & 3.8 & $<0.001$ \\
\hline
\end{tabular}

Both study groups were similar in terms of the total leukocyte count. But platelet count was significantly lower in cases compared to controls ( $p$-value 0.010).

In the present study, statistically significant higher NRBC counts were seen in the perinatal asphyxia group in comparison to the control group( $p$ value $<0.001)$.

Table-6: Nucleated red blood cell counts in study groups

\begin{tabular}{|l|l|l|l|}
\hline \multicolumn{1}{|c|}{$\begin{array}{c}\text { NRBC count } \\
\text { (per100WBC) }\end{array}$} & \multicolumn{1}{|c|}{$\begin{array}{c}\text { Cases -Number } \\
(\%)\end{array}$} & \multicolumn{1}{|c|}{$\begin{array}{c}\text { Controls- } \\
\text { Number(\%) }\end{array}$} & $\begin{array}{c}\text { p- } \\
\text { value }\end{array}$ \\
\hline $0-9$ & $2(4 \%)$ & $49(98 \%)$ & 0.000 \\
\hline $10-19$ & $31(62 \%)$ & $1(2 \%)$ & 0.000 \\
\hline 20 and more & $17(34 \%)$ & 0 & 0.000 \\
\hline
\end{tabular}

In the present study, statistically significant higher NRBC counts were seen in the perinatal asphyxia group in comparison to the control group( $\mathrm{p}$ value $<0.001)$. Most controls $(98 \%)$ had an NRBC count between 0 to 9 .

Only one control had an NRBC count between 10 to 19. None of the controls had an NRBC count of more than 20. Most cases (96\%) had an NRBC count of 10 or more.

31 cases $(62 \%)$ had NRBC count between 10 to19 and 17 cases (34\%) had an NRBC count of 20 or more. Only two cases had an NRBC count of less than ten.
Table -7: Comparison of NRBC count between the study group

\begin{tabular}{|l|l|l|l|}
\hline \multicolumn{1}{|c|}{ NRBC count } & \multicolumn{1}{c|}{ Cases } & \multicolumn{1}{c|}{ Controls } & p-value \\
\hline Mean \pm SD (per 100WBC) & $20.3 \pm 14.47$ & $3.8 \pm 3.09$ & 0.000 \\
\hline Range (per 100WBC) & 83 & 16 & \\
\hline Minimum (per 100WBC) & 7 & 0 & \\
\hline Maximum (per 100WBC) & 90 & 16 & \\
\hline
\end{tabular}

NRBC count was higher in cases compared to statistically significant controls.

$(P$-value $<0.001)$

Table -8: NRBC count and Apgar score at 1 minute and 5 minutes

\begin{tabular}{|l|l|l|l|}
\hline \multicolumn{2}{|c|}{ APGAR Score } & \multicolumn{1}{|c|}{ NRBC COUNT } & \multirow{2}{*}{ p-value } \\
\hline At 1 minute & $7-10$ & $3.80 \pm 3.09$ & $<0.001$ \\
\cline { 2 - 3 } & $4-6$ & $19.61 \pm 16.34$ & \\
\cline { 2 - 3 } & $0-3$ & $21.24 \pm 12.60$ & \multirow{3}{*}{$<0.001$} \\
\hline \multirow{4}{*}{ At 5 minute } & $7-10$ & $7.16 \pm 12.07$ & \\
\cline { 2 - 3 } & $4-6$ & $19.61 \pm 11.64$ & \\
\cline { 2 - 3 } & $0-3$ & $22.80 \pm 9.58$ & \\
\hline
\end{tabular}

Nucleated RBC count increased with decreasing Apgar score at both one minute and 5 minutes.

Table -9: Correlation between NRBC count and Apgar score at 1 minute and 5 minutes

\begin{tabular}{|l|l|l|}
\hline \multicolumn{1}{|c|}{ APGAR Score [Corelation Coefficient $(\boldsymbol{r})$ ] } & Case & Control \\
\hline At 1 minute & -0.627 & 0.084 \\
\hline$p$-value & 0.000 & 0.560 \\
\hline At 5 minute & -0.582 & 0.037 \\
\hline$p$-value & 0.000 & 0.797 \\
\hline
\end{tabular}

Nucleated RBC count was compared with Apgar score at1 and 5 minutes in both cases and controls group.

Among the cases, a statistically significant negative correlation exists between NRBC count and Apgar score at1-minute as well as at 5- minutes. No such correlation was found among the controls.

Table -10: Correlation of NRBC count with various immediate outcomes in cases

\begin{tabular}{|c|c|c|c|c|c|}
\hline Parameter & $\begin{array}{l}\text { Time is taken to start DBF in } \\
\text { days }\end{array}$ & $\begin{array}{c}\text { Neonatal reflex recovery in } \\
\text { days }\end{array}$ & $\begin{array}{c}\text { Cry/suck/activity recovery in } \\
\text { days }\end{array}$ & $\begin{array}{l}\text { NICU stay in } \\
\text { days }\end{array}$ & $\begin{array}{l}\text { Total hospital stay in } \\
\text { days }\end{array}$ \\
\hline $\begin{array}{l}\text { Correlation } \\
\text { coefficient }\end{array}$ & 0.557 & 0.293 & 0.030 & 0.513 & 0.490 \\
\hline p-value & 0.000 & 0.002 & 0.030 & 0.000 & 0.000 \\
\hline
\end{tabular}

Among the asphyxiated babies, a statistically significant positive correlation exists between NRBC count and time taken to start direct breast feeding,
Recovery of neonatal reflexes, recovery of good cry, suck and activity, duration of stay in NICU and total hospital stay. 
Table -11: NRBC count and various immediate outcomes in cases

\begin{tabular}{|l|l|l|l|l|l|l|}
\hline $\begin{array}{c}\text { Gro } \\
\text { up }\end{array}$ & \multicolumn{1}{|c|}{$\begin{array}{c}\text { NRBC Count } \\
\text { (per100WBC) }\end{array}$} & $\begin{array}{l}\text { Time is taken to start DBF } \\
\text { in days }\end{array}$ & $\begin{array}{r}\text { Neonatal reflex recovery } \\
\text { in days }\end{array}$ & $\begin{array}{r}\text { Cry/suck/activity recovery } \\
\text { in days }\end{array}$ & $\begin{array}{c}\text { NICU stay in } \\
\text { days }\end{array}$ & $\begin{array}{l}\text { Total hospital stay in } \\
\text { days }\end{array}$ \\
\hline 1 & $0-9$ & $2.5 \pm 0.71$ & $2.00 \pm 0.00$ & $2.0 \pm 0.00$ & $2.5 \pm 0.71$ & $4.5 \pm 0.71$ \\
\hline 2 & $10-19$ & $4.87 \pm 2.3$ & $4.16 \pm 2.67$ & $4.0 \pm 2.65$ & $5.81 \pm 2.96$ & $8.26 \pm 3.3$ \\
\hline 3 & 20 and more & $7.11 \pm 2.46$ & $5.78 \pm 2.22$ & $5.56 \pm 1.81$ & $8.11 \pm 2.20$ & $12.11 \pm 2.1$ \\
\hline p value & 0.011 & 0.110 & 0.118 & 0.023 & 0.001 \\
\hline
\end{tabular}

The mean time is taken to start direct breastfeeding, recovery of neonatal reflexes, recovery of a good cry, suck and activity, duration of stay in NICU and total hospital stay was longest in group 3 followed by group 2 and was least in group 1. This was statistically significant for all immediate outcomes studied except for recovery of neonatal reflexes and recovery of a good cry, suck and activity.

Table -12: Deaths concerning NRBC count

\begin{tabular}{|l|l|l|l|l|}
\hline \multicolumn{1}{|c|}{$\begin{array}{c}\text { NRBC count } \\
\text { (per100WBC) }\end{array}$} & Cases & $\begin{array}{r}\text { Total hospital stay in } \\
\text { days }\end{array}$ & Deaths & $\begin{array}{c}\text { p- } \\
\text { value }\end{array}$ \\
\hline $0-9$ & $2(4 \%)$ & $4.5 \pm 0.71$ & 0 & 0.001 \\
\hline $10-19$ & $\begin{array}{l}31 \\
(62 \%)\end{array}$ & $8.26 \pm 3.3$ & 0 & \\
\hline 20 and more & $\begin{array}{l}17 \\
(34 \%)\end{array}$ & $12.11 \pm 2.1$ & $8(47 \%)$ & \\
\hline
\end{tabular}

There was a total of 8 deaths in the study. All deaths occurred in the cases with NRBC count 20 and more.47\%of total cases with NRBC count of 20 or more died. This group also had a significantly longer hospital stay compared to other groups which was statistically significant ( $p$-value0.001)

\section{Discussion}

In the present study there were 50 babies in both study groups. There was no significant difference in the sex distribution of babies between the two study groups. The two study groups were similar in terms of age and parity of the mother. The mean birth weight of babies in the case group was nearly 130 gms more than the mean birth weight of the babies in the control group, but this difference was not statistically significant $(p=0.071)$. Gestational age was higher in cases compared to controls, which was statistically significant.

$62.5 \%$ of cases were associated with meconiumstained amniotic fluid. Other risk factors associated with birth asphyxia were a cord around the neck, the prolonged second stage of labour, secondary arrest in the descent of the fetus and short stature.
There was no statistically significant difference in the mode of delivery between the two study groups although more number of babies with birth asphyxia were born of assisted (forceps) vaginal delivery.

In the present study, the NRBC count for normal neonates was found to be $3.8 \pm 3.09$ NRBC/100WBC, which was consistent with previous reports $[15,16,17]$. NRBC count/100leukocytes increased during the first few hours of life in perinatal asphyxia as compared with healthy control subjects. The mean NRBC count in asphyxiated babies was $20.3( \pm 4.47)$ NRBC/100WBC, ranging from 7 to 93. Hence, the NRBC count was significantly higher in the asphyxiated group compared to normal babies ( $p$-value $<0.001$ ).

The mechanism causing the rapid release of NRBC following perinatal asphyxia is not known, although increased erythropoietin results from hypoxia and probably has a major role in the process $[17,18$,$] .$ NRBCs are immature erythrocytes whose production is thought to be driven primarily by the interplay of hypoxia and erythropoietin (EPO) synthesis [14].

Previous studies suggest that EPO increases erythroid production and releases immature forms of erythrocytes into the peripheral circulation in response to hypoxia. It is possible that increased NRBC production in the immediate neonatal state primarily reflects hypoxic injury [19]. Several studies have reported an increased NRBC in neonatal blood following perinatal asphyxia $[16,18,20,21,22,23]$.

Boskabadi et al [16] reported a cut-off value for NRBC as $>70 / \mathrm{mm} 3$ with a sensitivity of $83.4 \%$ and specificity of $73.5 \%$ in predicting perinatal asphyxia. The results of the present study give additional support to previous reports and also defines the cutoff value for NRBC as $>9 / 100 \mathrm{WBC}$ with a sensitivity of $96 \%$ and specificity of $94 \%$ in predicting birth asphyxia.

Neonates diagnosed with HIE were found to have higher NRBC counts, when compared with control infants. NRBC count was significantly related to the 
Sarnat's grading of encephalopathy and also elevated in infants who subsequently died when compared to those who survived. Ferns et al reported similar significant difference in the NRBC count between cases Vs controls and between various stages of $\operatorname{HIE}(p<0.001) .10$ Phelan et al showed that neonates with neurological impairment secondary to perinatal asphyxia had a significantly higher number of NRBC than the control group $(p<0.001) .30$ Fotopoulos et al. reported that increase in the number of NRBC is an early marker for subsequent neurological impairment [24].

Nucleated red blood cells are commonly seen in the cord blood of healthy newborns at birth. In term non-asphyxiated newborns, the number of nucleated red blood cells is variable but is only rarely higher than10/100WBC. The mechanism causing the rapid release of NRBC following perinatal asphyxia is not known, although increased erythropoietin results from hypoxia and probably has a major role in the process $[17,18]$.

Several studies have reported an increased NRBC in neonatal blood following perinatal asphyxia $[16,18,20,21,22,23]$. Boskabadi et al [16] reported a cut-off value for NRBC as $>70 / \mathrm{mm} 3$ with a sensitivity of $83.4 \%$ and specificity of $73.5 \%$ in predicting perinatal asphyxia. The results of the present study give additional support to previous reports and also defines the cut-off value for NRBC as $>9 / 100 W B C$ with a sensitivity of $96 \%$ and specificity of $94 \%$ in predicting birth asphyxia.

Neonates diagnosed with HIE were found to have higher NRBC counts, when compared with control infants. NRBC count was significantly related to the Sarnat's grading of encephalopathy and also elevated in infants who subsequently died when compared to those who survived. Ferns et al reported a similar significant difference in the NRBC count between cases Vs controls and between various stages of $\operatorname{HIE}(p<0.001) .10$ Phelan et al showed that neonates with neurological impairment secondary to perinatal asphyxia had a significantly higher number of NRBC than the control group $(p<0.001)$ [18]. Fotopoulos et al. reported that an increase in the number of NRBC is an early marker for subsequent neurological impairment [24]. it is comparable with our study.

Hanlon-Lundberg and Kirby [15] evaluated the relation between the severity of asphyxia and increased NRBCs by comparing cord NRBCs with cord $\mathrm{pH}$ and Apgar scores.
The NRBC counts increased with progressive increases in cord acidosis and with progressive decreases in the Apgar scores. 23 In the present study, a statistically significant negative correlation was demonstrated between NRBC per 100 WBC count and Apgar score at 1 minute.

Dasari et al [25] in a study reported a significantly higher mean NRBC count in babies with a low five minute Apgar score.82 Ferns et al observed a significant difference between the mean NRBC count of the term healthy babies and babies with perinatal asphyxia having a low Apgar score at five minutes $(p<0.001)$.

10 Similarly Hanlon-Lundberg et al [15] reported an inverse relationship between Apgar scores at both one and five minutes and NRBC count, but it was not statistically significant for Apgar score at five minutes.31 In the present study, a statistically significant negative correlation was demonstrated between NRBC per 100 WBC count and Apgar score at 5 minutes.

In the present study, a statistically significant positive correlation was found between NRBC count and time have taken to start direct breastfeeding, recovery of neonatal reflexes, recovery of a good cry, suck and activity, duration of stay in NICU and total hospital stay. ( $p$-value $<0.05$ ). The literature search did not yield any study comparing NRBC count with the recovery of neurological impairment after birth asphyxia and with a duration of hospital/NICU stay.

According to Boskabadi et al [16], the NRBC/100 leukocyte and absolute NRBC were significantly higher in neonates with adverse outcomes than in those with favourable outcomes (4.90 vs. 24.25 and 74.38 vs. 899 , p-value <0.001).65 In the present study, the NRBC count in the neonates with adverse outcome was significantly higher when compared to those with favourable outcome (29.62 \pm 18.30 vs $13.55 \pm 3.84$. p-value $<0.001$ )

According to Boskabadi et al [16], and NRBC count of greater than $13 / 100$ leukocytes had a sensitivity of $81.3 \%$ and a specificity of $94.4 \%$ in predicting adverse outcomes. In our study NRBC count cut-off of $>27 / 100$ WBC has a sensitivity of $75 \%$ and specificity of $95.2 \%$ in predicting adverse outcome defined as death, hemiplegia, hypertonia or significant hypotonia, unreliable sucking and seizures resistant to Phenobarbital. There were a total of 8 deaths in the study. 
All these deaths were in babies with birth asphyxia and all deaths were associated with an NRBC count of more than $20 / 100$ WBCs. $47 \%$ (i.e. 8 out of 17 ) of newborns with NRBC count more than 20 died in the early neonatal period.

Summary: A one-year case-control study to know the relation between peripheral venous blood nucleated red cell count collected within 6 hours of birth and perinatal asphyxia was carried out in the Department of Paediatric, SCB MEDICAL COLLEGE /SVPPGIP. The total number of babies enrolled was 100 (50 cases and 50 controls).

In the present study there were 50 babies in both study groups. There was no significant difference in the sex distribution of babies between the two study groups. The two study groups were similar in terms of age and parity of the mother. The mean birth weight of babies in the case group was nearly 130 gms more than the mean birth weight of the babies in the control group, but this difference was not statistically significant $(p=0.071)$.

Gestational age was higher in cases compared to controls, which was statistically significant. $62.5 \%$ of cases were associated with meconium-stained amniotic fluid. Other risk factors associated with birth asphyxia were a cord around the neck, the prolonged second stage of labour, secondary arrest in the descent of fetus and short stature.

There was no statistically significant difference in the mode of delivery between the two study groups although more number of babies with birth asphyxia was born of assisted (forceps) vaginal delivery. Babies born of emergency LSCS were excluded from both study groups.

In the present study, the mean ( \pm SD) NRBC count in normal term newborns born of normal vaginal delivery was $3.8 \pm 3.09 \mathrm{NRBC} / 100 \mathrm{WBC}$ (range 0 16). The mean NRBC count in asphyxiated babies was $20.3( \pm 4.47)$, ranging from 7 to 93 which was significantly higher when compared to normal newborns ( $p$-value < 0.001). The NRBC cut-off value of $>9 / 100 W B C$ has a sensitivity of $96 \%$ and specificity of $94 \%$ in predicting birth asphyxia defined as Apgar score $\leq 6 / 10$ at 1 - minute.

A statistically significant negative correlation was present between NRBC per 100 WBC count and Apgar scores at 1 minute and 5 minutes. A significant positive correlation was also established between NRBC count and HIE.
Also, a significant positive correlation was found between NRBC count and time have taken to start direct breastfeeding, recovery of neonatal reflexes, recovery of a good cry, suck and activity, duration of stay in NICU and total hospital stay.

The NRBC count was significantly higher in neonates with adverse outcomes than in those with favourable outcomes ( $p$-value $<0.001$ ). NRBC count cut-off of $>27 / 100$ WBC had a sensitivity of $75 \%$ and specificity of $95.2 \%$ in predicting adverse outcome defined as death, hemiplegia, hypertonia or significant hypotonia, unreliable sucking and seizures resistant to Phenobarbital.

The present study establishes a relationship between NRBC count and perinatal asphyxia and its outcome. It also defines the NRBC count cut-off value of $>27 / 100 W B C$ as a predictor of adverse outcome.

\section{Limitation of the study}

The present study includes only the baby born in term \& by normal vaginal route. So the result could not be generalized to the newborn population. The study was limited up to discharge; so long term outcome could not be determined.

\section{Conclusion}

Nucleated red blood cell count can be used as a surrogate marker for birth asphyxia. It has a significant negative correlation with Apgar score at one minute and Apgar score at 5minutes \& significant positive correlation with severity of hypoxic ischemic-encephalopathy, time is taken for recovery of neurological impairment following birth asphyxia and duration of NICU stay. The NRBC cutoff value of $>9 / 100$ WBC has a sensitivity of $96 \%$ and specificity of $94 \%$ in predicting birth asphyxia, defined as Apgar at 1 minute $\leq 6 / 10$. NRBC count cut-off of $>27$ per 100 WBCs has a sensitivity of $75 \%$ and specificity of $95.2 \%$ in predicting adverse short term outcome including early neonatal death in perinatal asphyxia.

\section{What does this study add to the existing knowledge?}

Nucleated RBC count in peripheral venous blood is a low cost, simple and easily available test which can be done in any health care facility with minimal infrastructure. 
In our country, a large number of deliveries occur in peripheral health facilities and at home by trained and untrained birth attendants. In such cases, accurate and reliable recording of well-established markers of birth asphyxia like Apgar scores, intranatal tocography recording for fetal distress, fetal scalp $\mathrm{pH}$ monitoring is often not available. Such babies pose diagnostic dilemmas for treating doctors in tertiary health care centres where these babies are referred. Early and accurate diagnosis of birth asphyxia is crucial in determining both short term and long-term prognosis. Cord blood NRBC count has been established as a marker of perinatal asphyxia in many previous studies. The present study establishes the role of NRBC count in peripheral venous blood collected within 6 hours of birth in diagnosis and prognostication of birth asphyxia. Hence this simple and reliable test can routinely be included in the investigation of all newborns with suspected birth asphyxia for diagnosis as well as prognosis.

\section{Contribution of a different author}

\begin{tabular}{|l|l|}
\hline \multicolumn{1}{|c|}{ Author } & \multicolumn{1}{c|}{ Contribution } \\
\hline Pradeep Kumar Jena & Study concept, design, method \\
\hline Himansu Kumar Parida & Literature, data collection, method \\
\hline Banashree Swain & Design, method, data collection \\
\hline Mangal Charan Murmu & $\begin{array}{l}\text { Data analysis, and manuscript preparation and } \\
\text { editing. }\end{array}$ \\
\hline
\end{tabular}

\section{Reference}

01. Pitsawong C, Panichkul P. Risk factors associated with birth asphyxia in Phramongkutklao Hospital. Thai J Obstet Gynaecol. 2012;19(4)165-171.

[Crossref]

02. John P Cloherty, Eric C Eichenwald, Ann R Stark. Manual of neonatal care. sixth editionLippincott Williams \& Wilkins. 2007;536556,623-633.

[Crossref]

03. Costello A, Francis V, Byrne A, Puddephatt C. State of the world's newborns. Kinetik communications. 2001.

[Crossref]

04. NNPD Network. Neonatal Neonatal-Perinatal Database, Report 2002-2003. Deorari A, ed, New Delhi- Indian Council of Medical Research. 2005.

[Crossref]
05. World Health Organization. Neonatal and Perinatal Mortality; Country, Regional and Global estimates,2004. Geneva- WHO, 2006;1-25. [Crossref]

06. Buonocore G, Perrone S, Longini M, Paffetti P, Vezzosi P, Gatti MG et al. Non protein bound iron as early predictive marker of neonatal brain damage. Brain. 2003;126(5)24-30.

doi: $10.1093 /$ brain/awg116 [Crossref]

07. Ferber A, Minior VK, Bornstein E, Michael Y, Divon F. "Non reassuring status" is associated with elevation of nucleated red blood cell counts and interleukin-6. Am J Obstet Gynecol. 2005; 192(5)1427-9. doi: $10.1016 /$ j.ajog.2004.12.076 [Crossref]

08. Ecker JL, Partridge JC, Prenner JL, Parer JT, Barkovich AJ. Predictors of magnetic resonance imaging abnormalities in asphyxiated neonates. Am J Obstet Gynecol. 1997;176(1)S61.

[Crossref]

09. Holla RG. Preventive strategies in HIE- Current status. J Neonatol. 2006;20(2)126-133.

[Crossref]

10. Ferns SJ, Bhat BV, Basu D. Value of nucleated red blood cells in predicting severity and outcome of perinatal asphyxia. Indian J Pathol Microbiol. 2004;47(4)503-4.

[Crossref]

11. Phelan J, Kirkendall C, Korst L, Martin G. Nucleated red blood cells in fetal brain injury show a consistent relationship with the intrapartum FHR pattern. Am J Obstet Gynecol. 2003;189(6)S165.

[Crossref]

12. Bonebrake R, Kelly A, Fleming A. An update on nucleated red blood cells as an indicator of fetal asphyxia. Am J Obstet Gynecol. $2001 ; 185(6)$ S246.

[Crossref]

13. Buonocore G, Perrone S, Gioia D, Gatti MG, Massafra C, Agosta R, et al. Nucleated red blood cell count at birth as an index of perinatal brain damage. Am J Obstet Gynecol. 1999;181(6)1500-5.

[Crossref] 
14. Ferber A, Fridel Z, Weissmann-Brenner A, Minior VK, Divon MY. Are elevated fetal nucleated red blood cell counts an indirect reflection of enhanced erythropoietin activity?. Am J Obstet Gynecol. 2004;190(5)1473-5.

[Crossref]

15. Hanlon-Lundberg KM, Kirby RS. Nucleated red blood cells as a marker of acid emiainterm neonates. Am J Obstet Gynecol. 1999;181(1)196-201.

[Crossref]

16. Boskabadi $H$, Maamouri $G H$, Sadeghian $M H$, Ghayour-Mobarhan M, Heidarzade M, Shakeri MT. early diagnosis of perinatal asphyxia by nucleated red blood cell count- Acase control study. Arch Iran Med. 2010;13(4)275-81.

[Crossref]

17. Saracoglu F, Sahin I, Eser E, Gol K, Turkkani B. Nucleated red blood cells as a marker in acute and chronic fetal asphyxia. Int J Gynaecol Obstet. $2000 ; 71 ; 113-18$.

[Crossref]

18. Phelan JP, Ahn MO, Korst LM, Martin GI. Nucleated red blood cells- a marker for fetal asphyxia?. Am J Obstet Gynecol. $1995 ; 173 ; 1380-4$.

[Crossref]

19. Dulay AT, BuhimschiI , Zhao G, LuoG, AbdelRazeq S, Cackovic M, et al. Nucleated red blood cells are a direct response to mediators of inflammation in newborns with early- on set neonatal sepsis. Am J Obstet Gynecol. 2008; 198;426-29.

[Crossref]
20. Ghosh B, Mittal S, Kumar S, Dadhwal V. Prediction of perinatal asphyxia with nucleated red blood cells in cord blood of newborns. Int J Gynaecol Obstet. 2003;81(3)267-71. [Crossref]

21. Thilaganathan B, Athanasious $S$, Ozmen $S$, CreightonS, Watson NR, Nicolaides $\mathrm{KH}$. Umbilical cord blood erythroblast count as an index of intrauterine hypoxia. Arch Dis Child Fetal Neonatal Ed. 1994;70(3)F192-4.

[Crossref]

22. Phelan JP, Korst LM , Young OckAHN, Martin GI. Neonatal nucleated red blood cell and lymphocyte counts in fetal brain injury. Obstet Gynecol. 1998;91485-9.

[Crossref]

23. Hermansen MC. Nucleated red blood cells in the fetus and newborn. Arch Dis Child Fetal Neonatal Ed. 2001;84;211-15.

[Crossref]

24. Fotopoulos S, Pavlou K, Skouteli $H$, Papassotiriou I, Lipsou N, Xanthou M. Early marker of brain damage in premature low-birthweight neonates who suffered from perinatal asphyxia and/or infection. Biol Neonate. $2001 ; 79 ; 213-8$.

[Crossref]

25. Dasari P, Phani JG, Badhe BA. Cord blood nucleated red blood cell count a marker of fetal asphyxia. J Obstet Gynecol India. 2008;58(1)45-8.

[Crossref] 